\section{El barbijo es el mensaje}

\section{Face Mask is the Message}

\section{Julieta Rucq y Victoria Nannini}

\author{
Julieta Rucq es docente e investigadora de la Escuela \\ de Comunicación Social, Facultad de Ciencia Política \\ y Relaciones Internacionales, Universidad Nacional de \\ Rosario, Argentina. \\ E-mail: julircq@gmail.com
}

Victoria Nannini es docente e investigadora de la Escuela de Comunicación Social, Facultad de Ciencia Política y Relaciones Internacionales, Universidad Nacional de Rosario, Argentina.

E-mail: victoria.nannini@fcpolit.unr.edu.ar

\section{resumen}

Este trabajo se desprende de un seminario de investigación de Doctorado y su posterior artículo, centrado en reflexionar sobre la fugaz adopción del barbijo o tapabocas, en la vida cotidiana, como un medio, en los términos propuestos por Marshall McLuhan: todo medio es mensaje. En este sentido, el artículo pretende abordar las razones de su uso, la circulación de sentidos en la sociedad, así como los nuevos vínculos establecidos entre personas con renovadas significaciones del orden identitario. De esta forma, el cuerpo, los sentidos y la moda constituyen artilugios reconfigurados por este medio y permiten establecer comparaciones con otras culturas, como las orientales, respecto del uso tanto de velos, por aquellas musulmanas, islámicas y árabes, como de barbijos, implementados hace años por países como Japón.

\section{palabras clave}

barbijo / comunicación / cuerpo / sentidos / moda / medios

\section{summary}

The present work stems from a $\mathrm{PhD}$ research seminar and its subsequent article focused on reflecting on the fleeting adoption of face masks in everyday life, as a 'medium' in the terms proposed by Marshall McLuhan: all mediums are messages. So much so, this article aims to address the reasons for its use, the circulation of meaning within society, as well as the new bonds established between people with renewed meanings of identity. In this way, the body, the senses and fashion constitute devices reconfigured by this medium and allow comparisons to be made with other cultures, such as Eastern ones, regarding the use of veils by Muslims, Islamic and Arabs as well as face masks, which have been used in Japan for several years.

\section{keywords}

face mask / medium / communication / body / fashion / senses 
"El medio es el mensaje", la premisa de Marshall Mcluhan, invita a preguntarnos cómo sería la aplicación de esta idea en el contexto actual: una pandemia que amenaza los cuerpos, un espacio social mediado por nuevas prácticas y elementos que se instalaron para quedarse. En ese contexto, el barbijo como objeto, herramienta, medio, irrumpe nuestras vidas mediatizadas.

Pensar el barbijo como medio en términos mcluhanianos habilita a reflexionar sobre él, no simplemente como lenguaje o tecnología que abre las puertas a otros niveles sinestésicos, sino también como artefacto de moda, cual interfaz, que ha reconvertido y reconfigurado las significaciones de la identidad y la representación de las personas en el contexto actual.

El simple hecho de que, en Occidente, el barbijo únicamente ha sido utilizado en contextos ligados a la salud, por parte de médicos, odontólogos, cocineros, o en anteriores epidemias, y advertía una significación absurda para quien lo llevase por la calle (porque taparse la cara, uno de los principales medios de identificación entre las personas, alude en nuestras culturas puramente visuales, a la delincuencia, el juego, lo payasesco) hace de este accesorio la panacea del cuidado. Torna obscena la desnudez de las caras descubiertas de quienes osan no llevarlo (Han, 2020).

Para comprender la fugaz adopción del barbijo como medio es preciso visualizar su gramática y, así, poder vislumbrar cómo viene operando, a partir de ello, la construcción de sentido. La primera razón yace en el límite que este medio establece entre la vida y la muerte. Luego, está su imperativo de acatar las normativas de cada ciudad, comercio, comuna, etcétera, así como también su carácter de tecnología habilitadora de otros mundos sensoriales posibles. Por último, reparamos en su conversión en un accesorio más de la moda, cuyo uso admite diversas significaciones del orden identitario y de las cuestiones de género. Como sostiene Valdettaro: "La clave para entender cuál es el 'mensaje' de un 'medio' o 'tecnología' está en su capacidad para reconfigurar el ambiente de la época o, incluso para crear un ambiente totalmente nuevo, introduciendo nuevas escalas en relación con las configuraciones ambientales precedentes" (2011:15).

El barbijo o tapabocas como medio implica la reificación de la conciencia humana, y da lugar así a la materialización de ciertas funciones propias de la humanidad, como la tactilidad, la percepción y la cognición.

Las tétradas de McLuhan respecto de los medios y sus efectos constituyen la intensificación, la caducidad, la recuperación y la inversión (McLuhan y McLuhan, 2009). Si pensamos en que los sentidos siempre están materializados y comienzan desde las texturas, es posible reconocer un vínculo entre el barbijo y el cuerpo, que tal como aporta Le Breton, "no es una sucesión de indicadores sensoriales bien delimitados, sino una sinergia donde todo se mezcla" (2009: 45).

De esta forma, las tétradas que podemos advertir en este medio incluyen la intensificación de algunos sentidos, así como la anulación, el bloqueo, el ocultamiento y la atrofia de otros. Torna caduco el maquillaje -a excepción del de los ojos- y parte de la comunicación facial. A su vez, realiza una recuperación de su uso en etapas epidémicas, así como también la retrospección al momento primiti- 
vo del ambiente amniótico. Contrariamente, invierte dicho ambiente en una construcción individual y consciente de un espacio acústico particular, en protección de posibles amenazas del mundo exterior que responderá en gran parte a una razón colectiva.

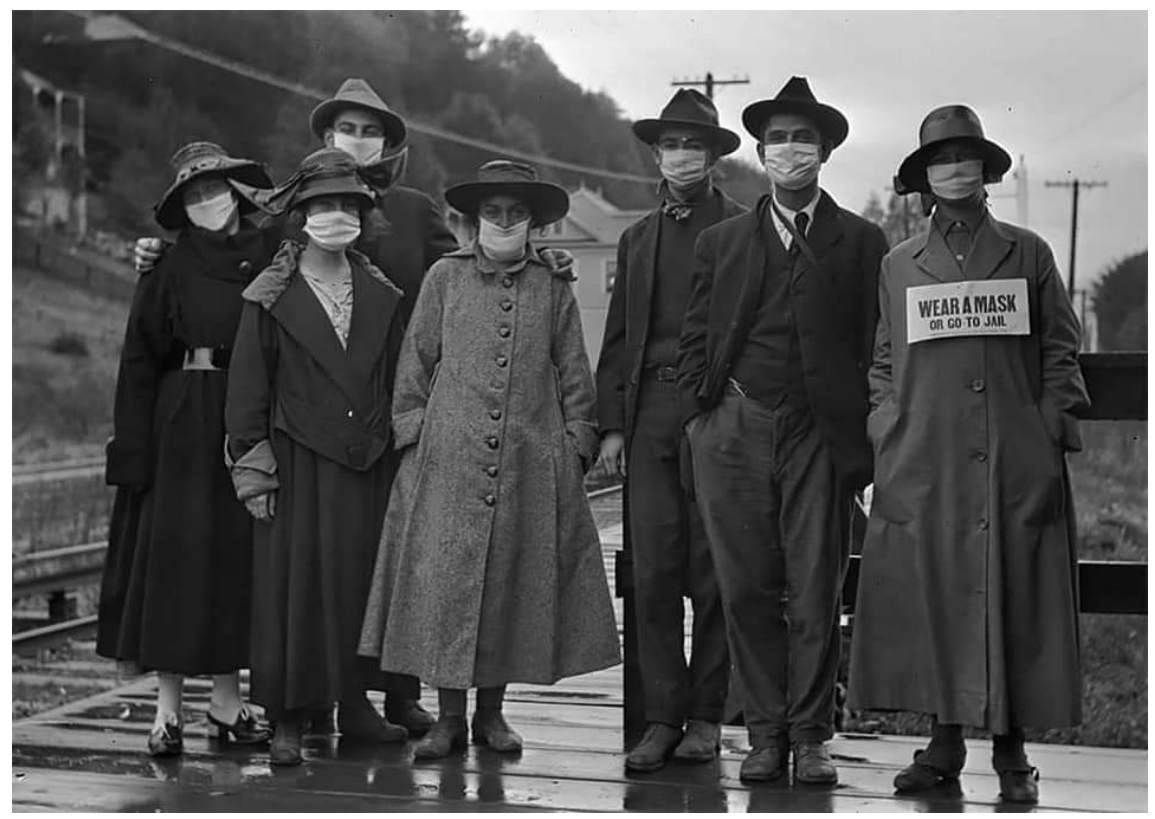

Imagen 1. Wear a mask

Por otra parte, el punto límite de este medio, luego de la etapa hipnótica de enamoramiento (Valdettaro, 2011), presenta embotamiento, por cuanto causa la falta de oxigenación, una dificultad para hablar y respirar, y su consiguiente complicación de cognición. A su vez, podemos nombrar otras limitaciones como el borramiento de la identificación, la dificultad de ingreso a ciertos espacios sin su uso y su intento de reemplazo por cualquier otra tela u objeto.

La configuración de este medio/interfaz, el barbijo o tapabocas (como lo mencionaremos a posteriori), ha redefinido actualmente el tipo de relaciones y vínculos sociales que se establecen entre las personas, y ha manifestado cómo, a partir de su uso obligatorio, se tramita la circulación de sentido. Su implementación genera consentimiento, respeto mutuo, cuidado. Establece una fina línea entre la vida y la muerte, el permiso para circular, trabajar y especialmente, para ser-en-elmundo compartido con amenazas bacteriológicas.

\section{El cuerpo, entre el mensaje y el medio}

Un cuerpo, cuerpos: no puede haber un solo cuerpo, y el cuerpo lleva la diferencia. Son fuerzas situadas y tensadas unas con otras. El "contra" (en 
contra, al encuentro, "cerquita") es la principal categoría del cuerpo. Es decir, el juego de las diferencias, los contrastes, las resistencias, las aprehensiones, las penetraciones, las repulsiones, las densidades, los pesos y medidas. Mi cuerpo existe contra el tejido de su ropa, los vapores del aire que respira, el resplandor de las luces o los roces de las tinieblas (Jean-Luc Nancy, 2010: 20).

El cuerpo se entiende como medio de expresión, como ser-en-el-mundo, atravesado por las significaciones culturales. Somos cuerpos que entran en intercambio, se relacionan y se comunican. Un contacto desde y con las corporalidades vincula entes, cosas, lugares y percepciones sensoriales que, en palabras de Le Breton, "dibujan los fluctuantes límites del entorno en el que vivimos y expresan su amplitud y sabor" (2009: 12). Así, el cuerpo aparece como mediador del mundo, como un filtro para apropiarse de lo que nos circunda. Hoy, estos vínculos se encuentran determinados por el contexto pandémico, en el cual el salir a la calle, transitar y encontrarse está mediado por nuevas prácticas y elementos. Allí el barbijo, en nuestro cuerpo, en contacto con nuestra piel, limita dos sentidos.

Así es que nadie está en completa posesión de su cuerpo, sino que cada quien es su cuerpo, lo habita. Son cuerpos que hoy están en peligro y que deben cuidarse para no ser infectados. En ese contexto, el barbijo es la protección, porque salir se presenta como una amenaza a nuestro ser.

Según Le Breton (2009), cada persona nunca es una oreja, un ojo, una mano, una boca o una nariz, sino más bien una mirada, una escucha, un tacto, una gustación o una olfacción; es decir, una actividad. Lo que se percibe es un mundo de significados y las experiencias son percibidas a través de nuestros cinco sentidos, que funcionan como mediadores con el exterior.

En las culturas occidentales, la mirada es el sentido hegemónico para cualquier desplazamiento, ya que la ciudad es una disposición de lo visual y una proliferación de lo visible. Así, la vista resulta ser el sentido más constantemente solicitado en nuestra relación con el mundo; abraza una multiplicidad de elementos. La mirada es suspensión sobre un acontecimiento, incluye la duración y la voluntad de comprender. "Explora los detalles, se opone a lo visual por su atención más sostenida, más apoyada, por su breve penetración" (Le Breton, 2009: 54). Mirar permite conocer y descubrir el mundo, el entorno, el detalle.

La vista requiere de otros sentidos -sobre todo del tacto- para ejercer su plenitud. La vista es siempre una palpación mediante la mirada, una evaluación de lo posible. Apela al movimiento y en particular al tacto. Prosigue su exploración táctil llevada por la mano, por los dedos, por la totalidad del cuerpo. Allí donde la mirada se limita a la superficie de las cosas, la mano contornea los objetos, va a su encuentro, los dispone favorablemente (Le Breton, 2009).

El sentido habilitado en este contexto continúa siendo la vista. El barbijo o tapabocas bloquea, reprime, limita y oculta el sentido del olfato y del gusto en nuestros recorridos en el espacio público. Estamos obligados a transitar por la calle con este nuevo elemento, que es parte de nuestra cotidianidad, pero implica un nuevo apren- 
dizaje en nuestra inmersión en el mundo. Este elemento, que podríamos considerar como medio, de acuerdo con McLuhan, ha reconfigurado nuestro ambiente y transformado de manera estructural la producción de nuevos hábitos perceptivos.

Si bien, tradicionalmente, nuestra cultura implica una valoración de lo visual por sobre otros sentidos, el hecho de que estén inhibidos en los recorridos que realizamos en la vía pública nos permite preguntarnos qué posibilita -evitar el contagio- y qué imposibilita el uso de este elemento. Somos una conjunción de sentidos. Entonces, si bien la vista está habilitada, el olfato y el gusto se encuentran imposibilitados.

[...] Concepto de visualidad emparentado con la tactilidad, considerado el "tacto" como juego recíproco de los sentidos, como sinestesia: es por ello, la era eléctrica, una era de con-tacto en la cual todo el aparato sensitivo -vista, sonido, movimiento, sabores, olores- se encuentra convocado (Valdettaro, 2011: 16).

Hoy, nuestro aparato sensitivo se encuentra reconfigurado, porque se usa plenamente en privado. Dentro de nuestros hogares podemos ser-en-el-mundo con todos los sentidos; afuera, no. Mientras que en Occidente esta forma de andar es particular, en Oriente, cubrirse la boca y la nariz, o toda la cara, tiene simbolismos espirituales, culturales y religiosos.

\section{Imagen 2. Musulmanas árabes con velos}
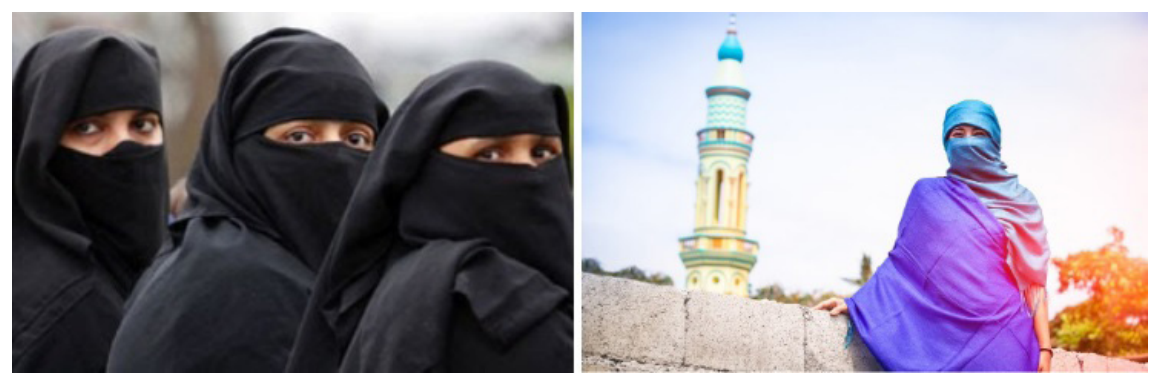

Más allá de cada caso, los velos sobre los rostros generan diferentes formas de relacionarse con el mundo. La presencia de mujeres que cubren zonas del cuerpo, a grandes rasgos, implica una barrera y un distanciamiento para ocultarse.

\section{Velos, feminismo y moda}

Pareciera mentira que, diez años atrás, Badiou (2010) denunciaba y parodiaba a sus compatriotas cuando exigieron una ley contra el velo en Francia. Badiou exclamó que un buen día se pidió que todas las personas salieran con sus cabezas descubiertas. El velo debía ser proscrito porque constituía un signo del poder de los machos -padres o hermanos mayores-sobre las musulmanas francesas. Por lo tanto, se penalizaría a aquellas que se obstinaran en llevarlos. 
En un tono irónico, concluía que estas jóvenes estaban oprimidas, ergo, debían ser castigadas " [...] la ley sobre el velo, es una ley capitalista pura. Ordena que la feminidad sea expuesta. Dicho de otro modo, que la circulación del cuerpo femenino bajo el paradigma mercantil sea obligatoria" (Badiou, 2010: 73-78).

Hasta no hace mucho tiempo atrás, la imagen de orientales con barbijos nos resultaba graciosa. Hemos llegado a sentir lástima por las mujeres de países árabes que deben y quieren llevar sus velos, burqah, kipa, hijab, sari o chador siguiendo sus costumbres. Las feministas han luchado por exigir su desestimación para "liberar a dichas mujeres".

De ninguna manera el uso del velo puede tener una correspondencia lineal con la opresión de las mujeres. En lugar de haber atacado las prácticas que conllevan el uso del velo, como reflexionó Badiou, intelectuales occidentales deberíamos alcanzar cierta consistencia respecto de nuestras propias prácticas sociales, sobre todo aquellas referidas a las mujeres y también a los prejuicios de clase. A su vez, es innegable que muchas prácticas relacionadas con el velo se han entremezclado indisolublemente en comunidades musulmanas, islámicas y árabes con prácticas patriarcales y autoritarias desligadas de la religión.

Los velos, impuestos o adaptados, suscitan connotaciones de sumisión, pero también de empoderamiento, porque liberan a las mujeres que los llevan de las obligaciones insidiosas de la moda occidental, así como de apreciaciones sexuales consecuentes. Desacreditar el uso del velo o intentar legislar sobre la materia es un error fatal pero, al mismo tiempo, pone de manifiesto la apremiante necesidad de reflexionar sobre la posible coexistencia de diversas creencias en el mundo contemporáneo, sobre la hibridación cultural junto con los desacuerdos sobre el rol de la mujer (Wilson, 2003).

En Malasia, el velo tiene una significación radical. Tiene connotaciones de clase que permiten dar cuenta de la pertenencia a una élite con cierta educación, esto es, una identidad que combina vida profesional, trabajo y la modestia de las creencias islámicas. A veces, el velo se constituye como un signo de liberación más que de opresión, ya que devuelve a las musulmanas el control total sobre sus cuerpos. Incluso, es combinado con prácticas occidentales de moda.

A partir de cualquiera de aquellas formas de vestimenta, propias de culturas árabes u orientales, se ha proclamado una oportunidad para muchas mujeres de no ser juzgadas por su belleza, como en Occidente, sino por sus personalidades y sus actos. Esto se contrapone con la otra visión que nos arroja un mundo post-capitalista e hiperglobalizado, donde los medios juegan un rol preponderante para tratar de dictar ciertas determinaciones, a través de la indumentaria, acerca de cómo debemos lucir y cómo deben ser nuestros estilos de vida. La libertad, en cualquier caso, está en juego de múltiples formas. Actualmente, nuestra perspectiva ha cambiado rotundamente, porque cubrirse es normativo.

Por lo tanto, ya sea mediante el uso de un velo, hijab, burqah y, ahora, en todo el mundo el barbijo o tapabocas, cubrirnos las caras irrumpe con la amenaza de la anonimidad. Si bien el hábito del velo representa el conjunto de valores y creencias que defienden quienes lo llevan, la costumbre del barbijo viene a representar 
el lazo insoslayable de una población que actúa en masa ante el peligro, y que basa su accionar en lo individual y en lo colectivo. El barbijo o tapabocas hace eco de ese ocultamiento de la imperfección de los cuerpos propios del velo, y somete sus partes riesgosas para ser reservadas al ámbito sumamente privado e individual. Además, es el nuevo estandarte de la diferenciación y la expresión identitaria.

\section{Moda. Extensión de la piel y traducción de nuestras identidades}

En la transición del acostumbramiento a este nuevo medio, estamos experimentando una fase narcisista, ya que ha generado un encantamiento de la noche a la mañana. Desde su utilización en espacios de trabajo, más allá de los relacionados con la salud, hoy es posible vislumbrar en el uso del barbijo el cinismo propio de nuestra época. Aquello que nos torna iguales se vuelve el objeto que permite a las personas diferenciarse en su habitar el mundo. Aquello que solía remitir a la criminalidad tiene como contracara la obscenidad de ver la boca y las narices de las personas.

La materialización del uso del barbijo en un primer momento permite el reconocimiento de todas las personas como seres con características uniformes. Somos iguales; tenemos bocas y narices que debemos cubrir y proteger de un virus. Sin embargo, al mismo tiempo, es el accesorio que permite diferenciarnos de la otredad y ubicarnos en otra posición del espacio social (Simmel, 1934; Bourdieu, 1999).

Esta interfaz posibilita zonas de contacto, específicamente en el cruce de las miradas. Empezamos la etapa de juzgar a partir del barbijo, y si hablamos en términos de moda, a partir del tapabocas como si fuera, en efecto, una prenda más de nuestros atuendos cotidianos, una extensión de nuestra piel (McLuhan, Fiore y Agel, 1987).

El barbijo o tapabocas nos traduce. Es interesante cómo la indumentaria y sus percepciones asociadas revelan toda la trama de estereotipos que operan continuamente en la interacción social. Cuando percibimos a otras personas, las clasificamos en categorías previamente internalizadas -estructuras estructurantes- como "pobre", "profesional", "trabajadora" o "alguien como una". Esas clasificaciones determinan qué se espera de cada una de esas personas. Toda primera impresión, a manera de potente prejuicio, siempre proviene de la forma en la que una persona está vestida (Nannini, 2016).

Quienes atienden a la importancia de llevar un tapabocas con estilo buscan diseños, telas, estampas y hasta la exhibición de logos de marcas. Asimismo, surgen posibilidades de comunicación y militancia de ideas al momento en que los tapabocas presentan palabras que no se están pudiendo decir y se plasman como enunciados no verbalizados. Este artefacto dice algo de quien lo lleva. Admite ambigüedades respecto del género y dispone nuevas configuraciones creativas de quienes siguen la moda. 


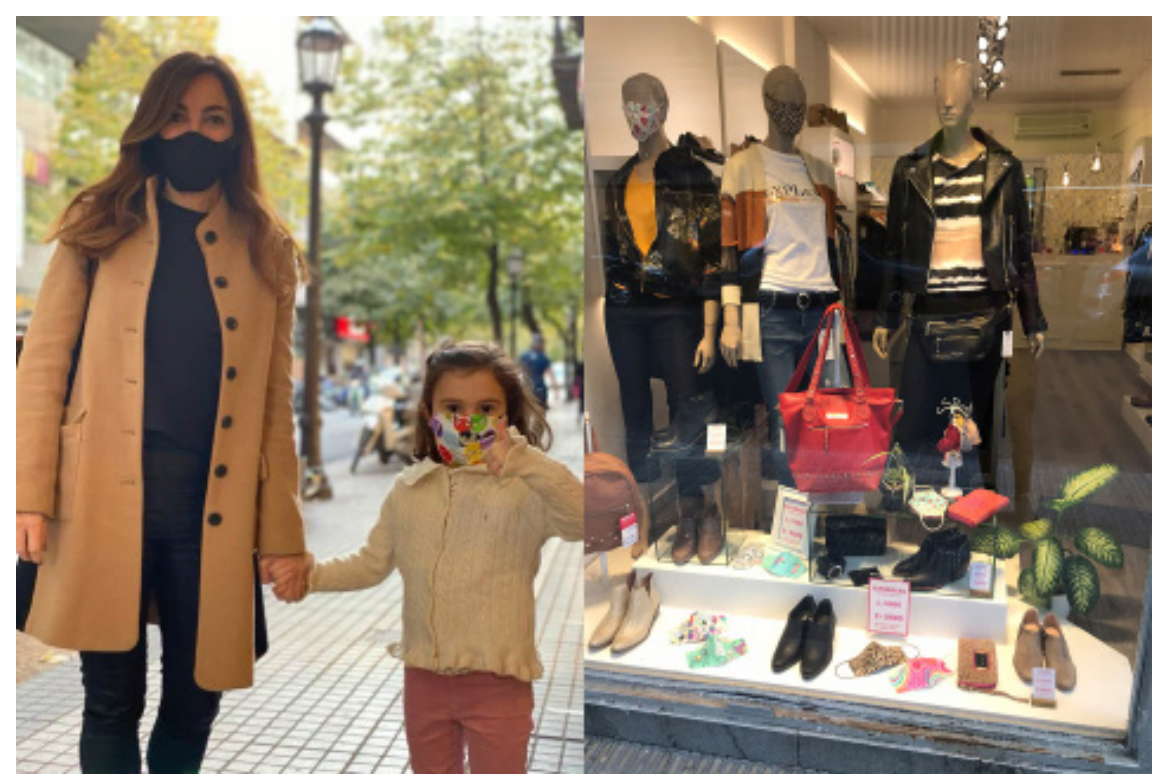

Imagen 3. Madre e hija con barbijos y vidriera exhibiendo barbijos

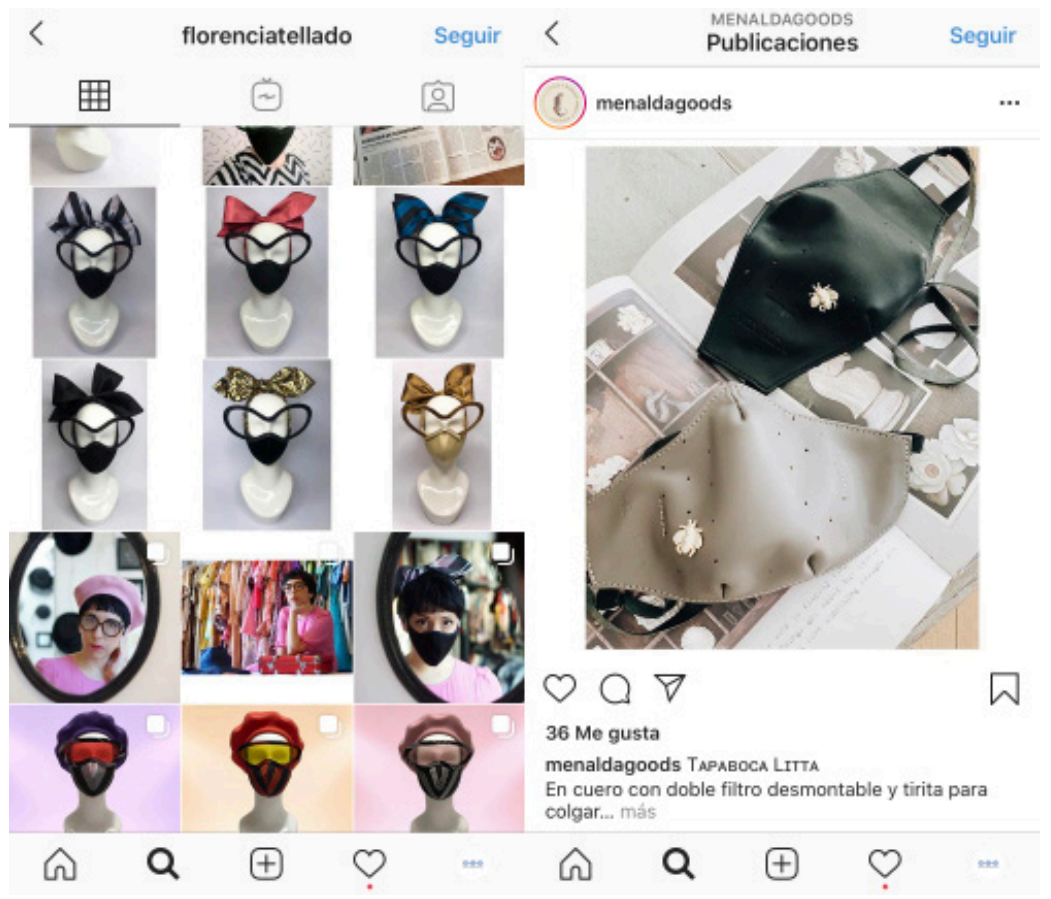

Imagen 4. Instagram con barbijos 
El diseñador Benito Fernández subraya que el barbijo condensa todo lo que nos está pasando. Este medio da lugar al statement, es decir, la afirmación de una identidad, borroneada por su mismo uso. ¿La paradoja? El lenguaje de nuestra época se traduce en que aquello que no podemos decir verbalmente lo afirmamos con un diseño en nuestras bocas, y hasta en gran parte de nuestras caras.

Zambrini (2019) afirma que la vestimenta, ya sea en su calidad consciente o inconsciente, refleja la expresión de nuestra identidad, pero también de la identidad colectiva, al evidenciar nuestra procedencia, nuestras costumbres, nuestra educación y cultura. La moda opera fuertemente en la pertenencia social, tanto sea para unir como para diferenciar. El barbijo o tapabocas resuelve el problema del contagio, la higiene, y se convierte además en signo de imitación/distinción.

Si bien nunca es directamente lineal la interpretación del lenguaje de la moda, cada elección estética resalta rasgos propios de la identidad. No podemos leer en el uso del barbijo o tapabocas la clase social de una persona, su orientación sexual, sus ideales políticos, pero sí podemos advertir algunas de sus preferencias, gustos, características de la personalidad y pertenencia a subculturas (hasta el momento, hemos podido observar personas adultas con tapabocas con parches de dibujos animados o equipos de fútbol).

\section{Los recorridos urbanos, la ciudad y el barbijo}

Nuestros cuerpos se adaptaron al espacio urbano, inmersos en la ciudad, acotados por sus construcciones, por sus reglas y por sus códigos. Nuestros desplazamientos están limitados a los recorridos que nos permite realizar su estructura. El cuerpo se encuentra atado a las estructuras urbanas, que lo llevan de un lado a otro según una ley anónima; poseído, jugador o pieza del juego. Michel De Certeau (2000) postula que la ciudad ofrece la capacidad de concebir y construir el espacio a partir de un número finito de propiedades estables, aisladas y articuladas unas sobre otras. Es un lugar de transformaciones y de apropiaciones.

Cada practicante de la ciudad, como forma elemental de esta experiencia, es un caminante, "cuyo cuerpo obedece a los trazos gruesos y a los más finos (de la caligrafía) de un texto urbano que escriben sin poder leerlo" (De Certeau, 2000: 105).

La calle se ha convertido en el espacio de enunciación de múltiples prácticas que se cuelan en los recorridos peatonales. Asimismo, quienes transitamos por las urbes enunciamos ideas y valores. Esto puede visualizarse tanto en la forma de andar, en los espacios por los que se circula, como en las vestimentas y accesorios de cada época. En ese sentido, hoy los recorridos están mediados por el tapabocas. Se trata de un accesorio de protección, pero también que dice. Es un medio, en términos de McLuhan, que nos calla, ante la dificultad de hablar con él, pero que a su vez enuncia, tal como venimos desarrollando.

El espacio urbano tiene la particularidad de estar conformado por no lugares, en términos de Marc Augé (2000), considerados como dos realidades complementarias: los espacios construidos con relación a ciertos fines -transporte, comercio, ocio-, y la relación que se establece con esos espacios. "Los no lugares mediatizan todo un conjunto de relaciones consigo mismos y con los otros que no apuntan 
sino indirectamente a sus fines: como los lugares antropológicos crean lo social orgánico, los no lugares crean la contractualidad solitaria" (Augé, 2000: 98). El no lugar crea la identidad compartida de los peatones, de los paseantes y ciclistas. "Solo, pero semejante a los otros, el usuario del no lugar está con ellos, pero en una relación contractual" (Augé, 2000: 105). Este espacio libera a quien lo penetra de sus determinaciones habituales, de sus roles cotidianos, ya que se encuentra en un anonimato relativo con una identidad provisional, y puede ser sentido como una liberación. Augé plantea que el espacio del no lugar no crea ni identidad singular ni relación, sino soledad y similitud. En la realidad concreta del mundo de hoy, los lugares y los no lugares se entrelazan e interpenetran. Estos no lugares, representados en los parques, en las esquinas, en las peatonales, son los espacios en los que hoy se encuentra la amenaza y, por ende, nuestra forma individual y solitaria de combatirla con el barbijo. Los no lugares son aquellos espacios en los que la pandemia se expande y, por eso, el uso de tapabocas es obligatorio. Allí es donde visualizamos el barbijo como medio, atravesado por una moda configurada desde lo político y por un cuerpo que no es libre, sino que se encuentra condicionado por su uso.

\section{Oriente vs. Occidente. Lo público y lo privado}

Arendt nos recuerda la diferencia entre la esfera pública y la privada en cuanto que se trata de "la distinción entre cosas que deberían estar ocultas y cosas que deberían ser mostradas" (1958: 72). A partir de esto, surge la riqueza múltiple de lo oculto bajo condiciones de intimidad. Para algunos países de Oriente, en específico para la población japonesa, el espacio público ampliamente circulado es el lugar del ocultamiento de ciertos rasgos corporales. Mujeres elegantes y hombres osados se esconden detrás de los barbijos. La piel es la intimidad.

Sin embargo, esto es sumamente paradójico. Aunque la piel se exhibe en lo más íntimo, también se la exhibe, sin pudores, en la intimidad de los baños públicos llamados onsen (masculinos y femeninos por separado). En el onsen, no hay vergüenza en desnudarse frente a quien se desconoce. Allí es correcto bañarse en total desnudez. Lo más llamativo, sin embargo, es que, en dichas culturas, la mirada es reconocida como una falta de educación y, por lo tanto, mirar a quien está enfrente es ofensivo. Entonces, la desnudez es privada y personal aun cuando es compartida en un espacio con otras personas desnudas.

Lo más extraño en la percepción del mundo por parte de esta sociedad es el sentido de lo que se denomina interior (内 $u c h i$ ) y exterior (外 soto). Dichos aspectos varían de persona a persona. Lo que vale la pena resaltar es que, para una japonesa, alguien que forma parte de su círculo íntimo (uchi) es de gran importancia. Esa persona debe ser honrada; no así quienes conforman su exterior (soto). Por eso, una japonesa puede desplegar todo su set de maquillaje en pleno subte, sin importar quién la pueda observar, siempre y cuando pueda presentarse correctamente ante una amiga, familiar o pareja.

La proxémica cumple otro valor esencial en este tipo de culturas. Acercarse demasiado para hablar con alguien representa la invasión del espacio físico. Por 
el contrario, apretujarse contra otros cuerpos en el transporte público asume un rango de mundanidad. No obstante, aun si todo nuestro cuerpo se encuentra enteramente en contacto con el de otra persona, cruzar la mirada sería algo totalmente inapropiado.

En Japón, la comunicación verbal entre personas -así como la proxémica- es relativamente pobre: los saludos interpersonales no existen entre personas extrañas. Dicha población intenta comunicarse principalmente a partir de su vestimenta. Con todo, su lenguaje es poco gestual. Lo no verbal se contrapone a la omnipresencia de una moda exagerada. El barbijo, entonces, constituye un accesorio cotidiano más, y suele ser customizado de múltiples formas.

Por otra parte, el uso del barbijo no es solo una demanda impuesta externamente, sino que parece haberse convertido en una práctica social integrada como parte del arsenal de responsabilidad individual en pos de la buena salud. Una respuesta originalmente colectiva, basada en la ciencia ante una amenaza a la salud pública, se ha dispersado y convertido al día de hoy en una práctica generalizada que carece de un fin o propósito claro (Burgess y Horii, 2012).

El uso del barbijo se ha convertido en un ritual social improvisado velozmente. Primero fue de manera obligatoria, y en Japón hace varios años ya es una costumbre y otra forma de comunicar la personalidad. A través del mimetismo y la sincronización, casi como un contagio emocional, el uso del barbijo equivale a una acción conjunta, normativamente enraizada, y la sintonización de la sociedad en su conjunto. El sacrificio de la expresión facial individual le ha dado mayor importancia a la identidad colectiva. Al diluir las distinciones sociales más salientes, ha producido semejanza social y, al mismo tiempo, la búsqueda de una diferenciación de estilos. "El uso del barbijo ha reactivado la sensación del bien común de la esfera pública" (Baehr, 2008: 150).

\section{Consideraciones finales}

Cuando decimos que el barbijo es un medio consideramos que

al contrario de entender los medios como representando o reflejando un real, lo construyen. Los medios desde este punto de vista son lenguajes o ambientes: materialidades significantes que figuran lo real de modos específicos; organizadores de marcos perceptivos y patrones subjetivos; productores de determinados modos de lazos sociales y de sujetos colectivos (Valdettaro, 2011: 20).

Así, en este contexto, estamos aprendiendo nuevas formas de relacionarnos. Nos encontramos en una mediatización constante de nuevos elementos y, por consiguiente, nuevas prácticas que están configurando y reconstruyendo otras prácticas. Por estos tiempos que corren, usar un barbijo o tapabocas nos despierta otras curiosidades sobre las personas. Abre el camino de la moda en sus múltiples posibilidades de elección de diseños, nos hace renunciar a esa imperiosa necesidad de ver la boca y la nariz de las otras personas, el uso de maquillaje en esas zonas y, finalmente, nos permite distinguirnos con una prenda única, si así lo quisiéramos. 
El barbijo o tapabocas nos obliga a pensar en nuestra mirada sobre Oriente, sus prácticas y costumbres. Un velo no es un símbolo de resistencia; un barbijo ya no implica el absurdo. Estos elementos se han vuelto técnicas de camuflaje, armas de combate, de la identidad individual a la colectiva, ida y vuelta. Así como, en la esfera pública, el velo hace de la circulación con las normas y los espacios culturales un objeto de vigilancia e interrogación paranoide (Fanon, 2004), el barbijo disemina el control y la vigilancia disciplinaria de cada integrante de la sociedad que registra si el resto está cumpliendo con el deber de su portación.

El barbijo como medio, retomando a McLuhan, es sin dudas la posibilidad de construir nuevos ambientes. Suscita el despertar de la adivinanza de quiénes son otras personas, qué hacen, y la imposibilidad de juzgar por la cara si parecen o no delincuentes, pero sí de alertar si no lo llevan. Hoy atravesamos esta nueva realidad, y escribimos desde este ambiente en el que estamos incorporando prácticas y estéticas que son propias del momento y de la amenaza con la que estamos viviendo.

El barbijo ha llegado para solucionar el miedo virósico que no necesita de estrategias geopolíticas para desarrollarse, donde el virus es un puro medio sin mensaje (Valdettaro, 2020). El barbijo se desentiende de todo y emite muchos mensajes indescifrables. Es uno de los tantos mensajes que en la producción y circulación de sentido está mediatizando nuestras interacciones, así como lo hacen las tecnologías. Ya no podemos ser-en-el-mundo y con una otredad si no es en continua mediatización de pantallas y barbijos.

\section{Bibliografía}

Arendt, H. (1958). The Human Condition. Chicago, US: The Chicago University Press.

Augé, M. (2000). De los Lugares a los no Lugares. En M. Augé, Los No lugares, pp. 81-118. Barcelona, España: Gedisa.

Baehr, P. (2008). City Under Siege: Authoritarian Toleration, Mask Culture, and the SARS Crisis in Hong Kong. Networked Disease: Emerging Infections in the Global City, 138-151.

Badiou, A. (2010). Filosofía del Presente. Buenos Aires, Argentina: Capital Intelectual.

Bourdieu, P. (1999). La Distinción. Criterio y Bases Sociales del Gusto. Madrid, España: Taurus.

Burgess, A., y Horii, M. (2012). Risk, Ritual and Health Responsibilisation: Japan's 'Safety Blanket' of Surgical Face Mask-Wearing. Sociology of Health \& Illness, 34 (8), 1184-1198.

De Certeau, M. (2000). La Invención de lo Cotidiano. Artes de Hacer. Ciudad de México, México: Cultura Libre.

Fanon, F. (2004). Algeria Unveiled. En P. Duara (Ed.), Decolonization: Perspectives from Now and Then, pp. 42-55. New York, US - London, UK: Routledge.

Han, B. C. (2020). La Emergencia Viral y el Mundo de Mañana. En VV.AA., Sopa de Wuhan, pp. 97111. Buenos Aires, Argentina: Editorial ASPO (Aislamiento Social, Preventivo y Obligatorio).

Le Breton, D. (2009). El Sabor del Mundo. Una Antropología de los Sentidos. Buenos Aires, Argentina: Nueva Visión.

McLuhan, M., Fiore, Q. y Agel, J. (1987). El Medio es el Mensaje. Barcelona, España: Paidós.

McLuhan, M., y McLuhan, E. (2009). Las Leyes de los Medios. CIC. Cuadernos de información y Comunicación, 14, 285-316.

Nancy, J. L. (2010). 58 Indicios sobre el Cuerpo. Extensión del Alma. Buenos Aires, Argentina: Ediciones La Cebra. 
Nannini, V. (2016). Moda, Comunicación y Poder: ¿Qué vestimos, por qué y qué queremos decir con eso? Tesina de grado de la Licenciatura en Comunicación Social, Universidad Nacional de Rosario. Rosario, Argentina.

Simmel, G. (1934). Cultura Femenina. Madrid, España: Revista de Occidente.

Valdettaro, S. (2020). El Virus es el Mensaje. En VV.AA, El Futuro Después del Covid-19, pp. 151156. Buenos Aires, Argentina: Argentina Unida.

Valdettaro, S. (2011). El Dispositivo McLuhan: recuperaciones y derivaciones. Rosario, Argentina: UNR Editora.

Wilson, E. (2003). Adorned in Dreams. Fashion and Modernity. London, UK: IB Tauris.

Zambrini, L. (2019). Deshilando los géneros de la moda. En L. Zambrini y D. Lucena (Comps.), Costura y Cultura. Aproximaciones sociológicas sobre el vestir. La Plata, Argentina: Editorial Universidad Nacional de La Plata. 